\title{
Phylogenetic relationships and species differentiation of 39 Legionella species by sequence determination of the RNase P RNA gene $r n p B$
}

\author{
Carl-Johan Rubin, ${ }^{1}$ Mikael Thollesson, ${ }^{2}$ Leif A. Kirsebom ${ }^{3}$ \\ and Björn Herrmann ${ }^{1}$ \\ ${ }^{1}$ Department of Clinical Microbiology, University Hospital, SE-751 85 Uppsala, Sweden \\ ${ }^{2}$ Department of Molecular Evolution, EBC, Uppsala University, Norbyvägen 18C, SE-19530 \\ Uppsala, Sweden \\ ${ }^{3}$ Department of Cell and Molecular Biology, Box 596, Biomedical Centre, SE-75124 Uppsala, \\ Sweden
}

Correspondence

Björn Herrmann

bjorn.herrmann@medsci.uu.se

\section{INTRODUCTION}

The genus Legionella comprises more than 50 species (Park et al., 2004) and new species are frequently described (http:// www.dsmz.de/bactnom/bactname.htm). Some Legionella species cause human disease, while others have been detected only in the environment (Fields et al., 2002). The diseases caused by Legionella include the pneumonic form, Legionnaires' disease, and the extrapulmonary flu-like form, Pontiac fever. Legionella pneumophila serogroup (sg) 1 is the causative agent in up to $84 \%$ of disease cases that are due to Legionella infection ( $\mathrm{Yu}$ et al., 2002). There may, however, be a bias towards detecting L. pneumophila sg 1 ,

Published online ahead of print on 27 May 2005 as DOI 10.1099/ ijs.0.63656-0.

Abbreviations: AFLP, amplified fragment length polymorphism; NAIM, nucleotide analogue modification interference; $\mathrm{NJ}$, neighbour-joining; MLST, multilocus sequence typing; MP, maximum parsimony; sg, serogroup; SW, Shannon-Wiener.

The GenBank/EMBL/DDBJ accession numbers for the $r n p B$ sequences of 55 Legionella strains are AJ781429-AJ781483.

Tables showing the alignment of Legionella $r n p B$ gene sequences included in this study are available as supplementary material in IJSEM Online. since commonly used urinary antigen tests mainly detect this serogroup (Helbig et al., 2003). Other L. pneumophila serogroups, as well as Legionella longbeachae, Legionella micdadei, Legionella dumoffii and Legionella feeleii, are also often associated with human disease (O'Connell et al., 1996). In Australia, L. longbeachae is the leading cause of Legionnaires' disease (Alli et al., 2003). Immunocompromised individuals are especially susceptible to infection and may be colonized by species not normally associated with disease. Therefore, it is important for epidemiological investigations to identify species within the genus accurately.

In clinical diagnostics, Legionella bacteria are commonly identified by culture since they have very specific growth requirements. If bacteria grow on cysteine-enriched buffered charcoal-yeast extract (BCYE) agar, but not on BCYE agar without cysteine, the bacteria presumably belong to the genus Legionella (Murray et al., 2002). To discriminate between species, phenotypic tests such as growth characteristics, auto-fluorescence and serological methods targeting membrane proteins are often used. These methods provide low resolution and antigen cross-reactivity limits the specificity of antibody tests (Verissimo et al., 1996). 
Several DNA-based classification systems have been described for Legionella, some of which target the sequence variation of specific genes such as mip (Ratcliff et al., 1998), $16 \mathrm{~S}$ rRNA (Fry et al., 1991), rpoB (Ko et al., 2002) and gyrA (Feddersen et al., 2000). Analysis of transfer DNA intergenic spacer length polymorphism has been shown to be highly discriminatory in the identification of Legionella species (De Gheldre et al., 2001). Amplified fragment length polymorphism (AFLP) and multilocus sequence typing (MLST) are very discriminatory techniques for subtyping within the species L. pneumophila (Gaia et al., 2003), where they also distinguish within serogroups (Jonas et al., 2000; Valsangiacomo et al., 1995). Thus, DNA-based analyses have greatly improved Legionella phylogenetics and the ability to discriminate between bacteria within the Legionella genus.

The $r n p B$ gene encodes the catalytic RNA moiety of endoribonuclease $\mathrm{P}$ (RNase $\mathrm{P}$ ), the enzyme that removes the $5^{\prime}$ leader of precursor tRNAs. In Bacteria and some Archaea, the RNA component alone exhibits catalytic activity in vitro; however, the protein subunit $\mathrm{C} 5$ is essential for activity in vivo and is encoded by the rnpA gene (Altman \& Kirsebom, 1999; Pannucci et al., 1999). Based on the secondary structure of RNase P RNA, two types of bacterial RNase P RNA have been identified, type A and type B. RNase P RNA derived from Legionella belongs to type A, which is suggested to be the ancestral form of RNase P RNA found in
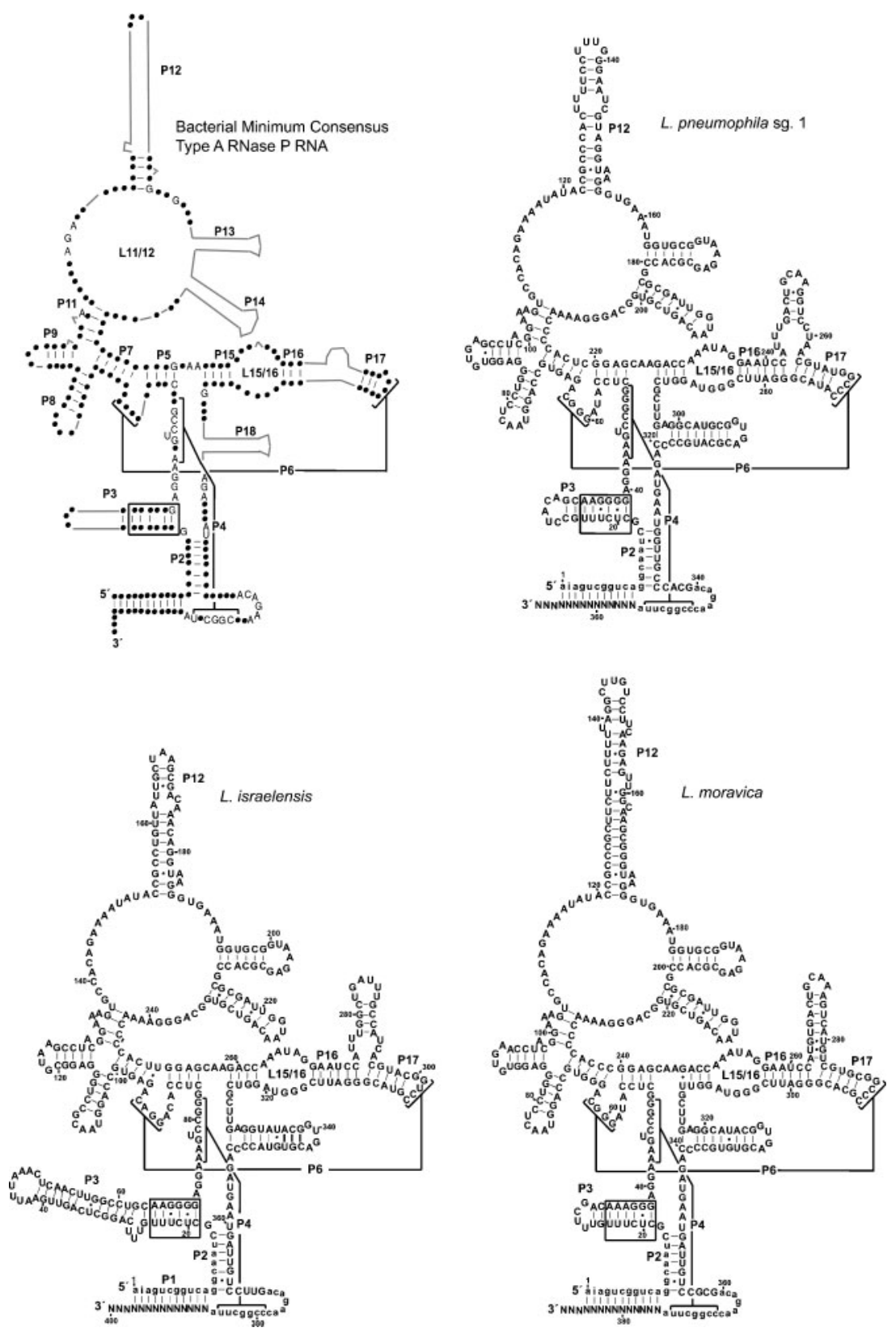

Fig. 1. Minimum consensus secondary structure of bacterial type A RNase P RNA and deduced secondary structures of RNase P RNA from Legionella pneumophila ATCC $33152^{\top} \mathrm{sg} 1$, Legionella moravica ATCC $42877^{\top}$ and Legionella israelensis ATCC $43119^{\top}$. Lower case letters indicate nucleotides in primer sequences and nucleotides denoted $\mathrm{N}$ are tentative nucleotides flanking the primers. Boxed nucleotides show positions proposed to interact with the C5 protein. 
bacteria. Type B RNase P RNA may have emerged later within the low $\mathrm{G}+\mathrm{C}$ Gram-positive lineage (Haas \& Brown, 1998).

In bacteria, $r n p B$ comprises about 400 nt (Pace \& Brown, 1995) and several conserved regions essential for the functioning of RNase P RNA have been identified. Certain regions with high variability have also been identified, for example, P3, P12 and P17 (see Fig. 1). The sequence variation of $r n p B$ has been used previously to differentiate closely related species of Chlamydiaceae (Herrmann et al., 2000) and Streptococcus (Tapp et al., 2003).

In this report, we investigate the phylogeny within the genus Legionella, discuss the interaction between RNase P RNA and the C5 protein and evaluate $r n p B$ as a tool for discriminating between Legionella species.

\section{METHODS}

Bacterial strains. The 55 Legionella strains (39 type strains and 16 additional reference strains) included in this study are listed in Table 1. Furthermore, 12 clinical and three environmental isolates (1777/97, 1780/97 and 1829/00) are detailed (see Fig. 5).

DNA preparation. DNA for PCR amplification was extracted either by using the Qiagen DNA mini kit or by using a phenol/ chloroform-based method.

PCR amplification. The $r m p B$ gene was amplified using the primer pair LP3 [5'CA(INOSINE)AGTYGGTCAGGCAAT-3'] and BM1-2 ( $5^{\prime}$-TGTAAAACGACGGCCAGTRTAAGCCGGGTTCTGT- ${ }^{\prime}$ '). The reaction mixture consisted of $0 \cdot 8 \mu \mathrm{M}$ of each primer, $200 \mu \mathrm{M}$ dNTPs, $2 \mathrm{mM} \mathrm{MgCl}$, 2 U HotStar Taq DNA polymerase (Qiagen) and 20-100 ng template DNA, as measured from semiquantitative measurement on ethidium bromide-stained agarose gels. The reaction mixture was subjected to enzyme activation for $15 \mathrm{~min}$ at $95^{\circ} \mathrm{C}$ followed by 37 cycles of amplification. Each amplification cycle consisted of denaturation for $30 \mathrm{~s}$ at $95^{\circ} \mathrm{C}$, primer annealing for $40 \mathrm{~s}$ at $50{ }^{\circ} \mathrm{C}$ and elongation for $40 \mathrm{~s}$ at $72{ }^{\circ} \mathrm{C}$. A final step of $7 \mathrm{~min}$ at $72^{\circ} \mathrm{C}$ was performed to ensure complete extension.

The 16S rRNA and mip genes of the environmental isolate 1829/00 were sequenced as described elsewhere (Johansson et al., 1995; Ratcliff et al., 1998).

Sequence analyses. Initially, partial $r m p B$ gene sequences were PCR-amplified with primers binding to the conserved regions defined by $\mathrm{P} 4$. The products generated by these primers, however, did not include the hypervariable P3 loop.

To facilitate the design of the LP3 primer, the sequence between the promoter region and the P3 loop was determined for ten Legionella species by amplifying the $5^{\prime}$-flanking DNA of the P4 loop in a PCR with biotinylated primers and streptavidin-coated beads, as described elsewhere (Sorensen et al., 1993). Sequencing of PCR products defined by LP3 and BM1-2 was performed on both DNA strands of all strains using polymer POP6 in an ABI 310 Genetic Analyser (Applied Biosystems). BM1-2 and LP3 were also used as primers in the sequencing PCR, in which the BigDye terminator-labelled cycle sequencing chemistry kit version 2.0 (Applied Biosystems) was used.

Phylogenetic analysis. The $r n p B$ gene sequences were aligned using CLUSTAL $\mathrm{W}$, but required some manual editing to align homologous sites according to the secondary structures of RNase P RNA. The 16S rRNA, mip and $r p o B$ gene sequences were obtained from
GenBank and their accession numbers are presented in Table 1. The $16 \mathrm{~S}$ rRNA and mip gene sequences varied in size, and sequences from some species were therefore trimmed at the ends to generate sequences with homologous sites in the CLUSTAL $\mathrm{W}$ alignments. The $r n p B$ fragments included were 304-354 nt long. 16S rRNA genes were approximately $1350 \mathrm{nt}$ in length. All $r p o B$ fragments were $300 \mathrm{nt}$ long and approximately $650 \mathrm{nt}$ were included from mip sequences, including the hypervariable insert adjacent to the signal sequence. The combined dataset, consisting of $r p p B, 16 \mathrm{~S}$ rRNA, mip and $r p o B$ gene sequences, was constructed by concatenating the alignments for the individual genes and included 39 Legionella species, of which 37 had sequences available for all four genes.

The alignments obtained (individual genes and concatenated alignments) were used for phylogenetic inference using a Bayesian approach as implemented in MrBayes 3.0B4 (Huelsenbeck \& Ronquist, 2001). MrBayes uses Metropolis-coupled Markov chain Monte Carlo methods to calculate the posterior probabilities for the parameters of interest. Each analysis was run for $1 \times 10^{7}$ generations with four differently heated chains; generations before convergence (as monitored on tree likelihood and total tree length) were discarded as burn-in.

To select an adequate model for the Bayesian analysis, as well as pairwise distances, we used a hierarchical likelihood ratio test approach (Huelsenbeck \& Crandall, 1997). To do this, we used PAUP* 4.0b8-10 Linux and Macintosh versions (Swofford, 2000) and the same test hierarchy (and thus model selection) as implemented in the modeltest program (Posada \& Crandall, 1998) at $P<0 \cdot 01$. Neighbour-joining (NJ) trees under the Jukes-Cantor model were produced for each of the datasets/partitions separately as well as in combination and the parameters for each model were estimated using these trees. The same model was used for the pairwise distances (e.g. gamma shape, proportion invariant sites) and the parameters assigned were based on the maximum-likelihood estimate.

In addition to the Bayesian analysis, we performed bootstrap analyses as implemented in PAUP ${ }^{\star} 4.0 \mathrm{~b} 8-10$, using maximum parsimony (MP) as optimality criterion and also using NJ. For the optimality criterion method, 1000 bootstrap replicates were performed and heuristic search algorithms were used, namely simple stepwise addition and tree bisection reconnection branch swapping.

To compare the variation in the different genes, we used the ShannonWiener information index, $H$, defined as

$$
H=-\sum_{i=1}^{4} p_{i} \log p_{i}
$$

where $p_{\mathrm{i}}$ is the proportion of A, T, C and G (Shannon \& Weaver, 1949; Wiener, 1949). The mean value for all sites in the same set of taxa was calculated for each dataset.

\section{RESULTS AND DISCUSSION}

\section{Sequence comparison of $r n p B$ in the genus Legionella}

PCR amplicons between 304 and 354 bp (primers excluded) were obtained, constituting $89-91 \%$ of the total $r n p B$ gene sequences. Partial $\operatorname{rnp} B$ gene sequences of 39 type strains were compared and the pairwise similarities ranged between $75 \cdot 1$ and $100 \%$, with Legionella micdadei ATCC $33218^{\mathrm{T}}$ and Legionella maceachernii ATCC $35300^{\mathrm{T}}$ as the only species having identical $r n p B$ gene sequences. These two species are difficult to distinguish from each other phenotypically and 
Table 1. GenBank accession numbers for the $r n p B, 16 \mathrm{~S}$ rRNA, mip and $r p o B$ gene sequences and sources of strains used

ATCC, American Type Culture Collection, Manassas, VA, USA; CCUG, Culture Collection University of Göteborg, Gothenburg, Sweden; SMI, Swedish Institute for Infectious Disease Control, Stockholm, Sweden.

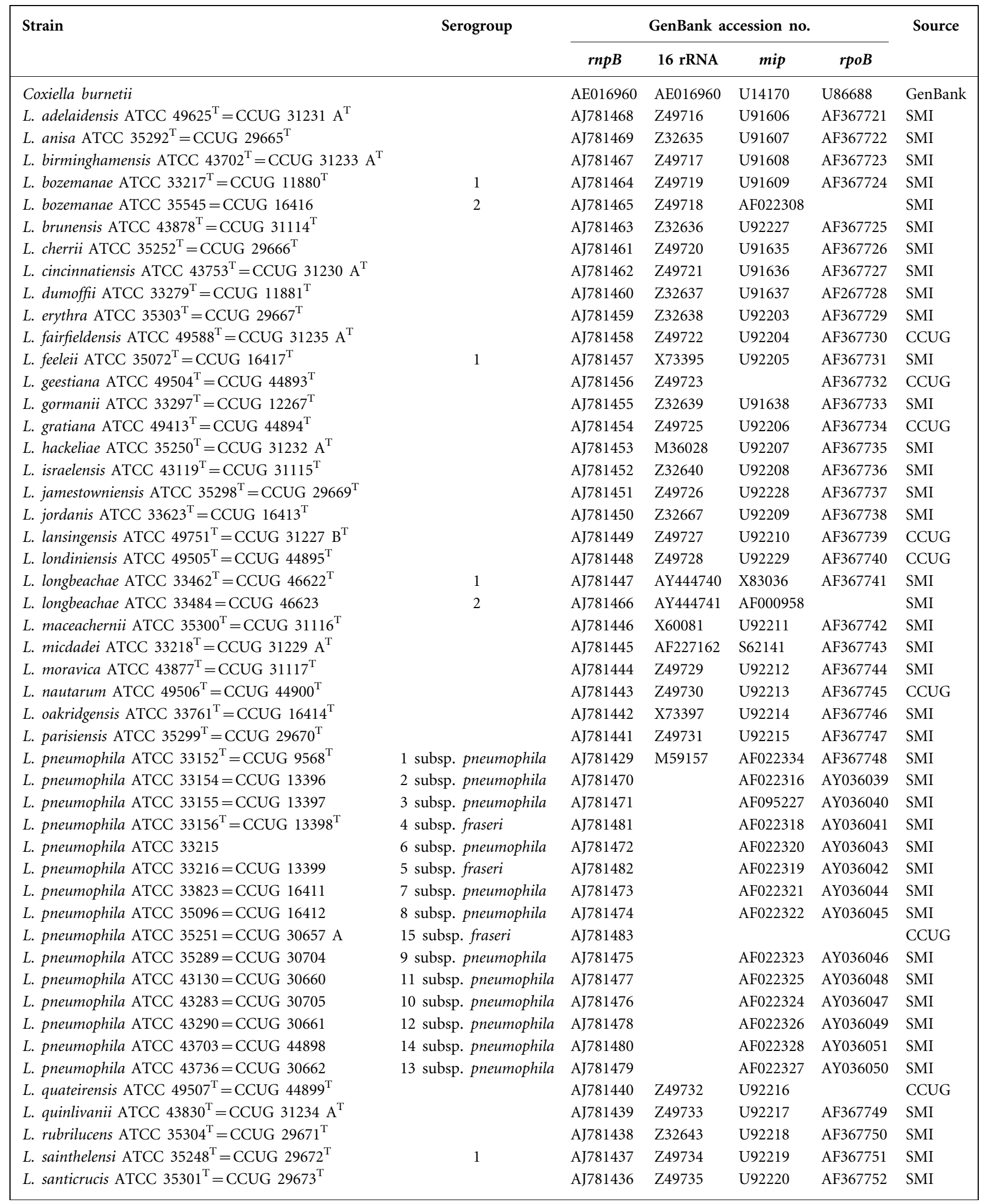


Table 1. cont.

\begin{tabular}{|c|c|c|c|c|c|c|}
\hline Strain & Serogroup & \multicolumn{4}{|c|}{ GenBank accession no. } & Source \\
\hline L. spiritensis ATCC $35249^{\mathrm{T}}=\mathrm{CCUG} 31118^{\mathrm{T}}$ & 1 & AJ781434 & M36030 & U92222 & AF367754 & SMI \\
\hline L. steigerwaltii ATCC $35302^{\mathrm{T}}=$ CCUG $29674^{\mathrm{T}}$ & & AJ781433 & Z49737 & U92223 & AF367755 & SMI \\
\hline L. tucsonensis ATCC $49180^{\mathrm{T}}=$ CCUG $31119^{\mathrm{T}}$ & & AJ781432 & Z32644 & U92224 & AF367756 & SMI \\
\hline
\end{tabular}

were previously referred to as the Tatlockia species (Fox et al., 1991); they are however distinguishable using mip gene sequencing.

Differentiation of Legionella bozemanae and Legionella anisa has been proven difficult by transfer DNA intergenic spacer length polymorphisms (De Gheldre et al., 2001). A close species relationship was found when comparing $r n p B$ gene sequences derived from these two Legionella species. In sequence analysis, L. anisa ATCC $35292^{\mathrm{T}}$ differs in four nucleotide positions compared with L. bozemanae ATCC 35545 sg 2, while the corresponding differences in comparisons between L. anisa ATCC $35292^{\mathrm{T}}$ and L. bozemanae ATCC $33217^{\mathrm{T}} \mathrm{sg} 1$, as well as between the two serogroups of L. bozemanae, were seven nucleotide positions. The finding that $\operatorname{rnpB}$ gene sequences from $L$. bozemanae sg 2 and $L$. anisa are more similar than those from the two serogroups of L. bozemanae was surprising since sequence data from previous studies examining other genes, such as mip and $r p o B$, have indicated a more distant relationship between the two species (Ko et al., 2002; Ratcliff et al., 1998).

The L. pneumophila serogroups 4, 5 and 15, together constituting L. pneumophila subsp. fraseri, differed in 14-15 nt from the $r p p B$ gene sequence of L. pneumophila ATCC $33152^{\mathrm{T}}$ sg 1, while the sequence variation within subspecies fraseri was $1 \mathrm{nt}$. Similarly, the sequence variation within the subspecies of L. pneumophila subsp. pneumophila varied between 0 and 4 nt.

\section{Secondary structures and intermolecular interactions of the RNase P RNA}

The RNase P RNA gene has been sequenced and characterized from a large number of different bacteria (Brown, 1999). This information has been incorporated into models of the three-dimensional structures of both types of RNase P RNA, as well as in a complex with the protein subunit (Massire et al., 1998; Tsai et al., 2003). The majority of these previous studies on bacterial RNase P RNA have, however, focused on structural and functional differences between members of different bacterial genera (Haas \& Brown, 1998). This study examined 39 species within one genus.
With the guidance of a type A RNase P RNA minimum consensus structure model (Brown, 1999), secondary structures of RNase P RNAs from three Legionella type strains were generated. As shown in Fig. 1, the secondary structures are very similar to those of some $\gamma$-Proteobacteria, e.g. Pseudomonas aeruginosa and Escherichia coli. Within the Legionella genus, RNase P RNA showed structural variations, particularly in P3 and P12 but also in the structural element between P16 and P17.

Two P3 variants were observed where the major variant was an 8 bp stem structure with a loop varying in size between three and six residues. In one species, Legionella israelensis ATCC $43119^{\mathrm{T}}$, the sequence suggested the existence of a P3 helix composed of 20 bp with a U-rich internal bulge and a loop with eight residues (Fig. 1). Moreover, we noted that the first 6 bp of P3 are highly conserved irrespective of Legionella species (boxed residues in Fig. 1; see also sequence alignment data in Supplementary Material in IJSEM Online). Likewise, comparison of RNase P RNA structures derived from closely related bacterial species, e.g. Mycoplasma species (Svard et al., 1994), also reveals that the length of P3 varies and that residues in the boxed region (Fig. 1) in P3 are conserved. In contrast, a comparison of the length and sequence variation of the P3 domain derived from different bacterial branches indicates that the structure of the P3 is highly variable (Haas \& Brown, 1998). The three-dimensional structural model of E. coli RNase P RNA (type A) in complex with the RNase P protein (C5) suggests that part of $\mathrm{P} 3$ interacts with the $\mathrm{C} 5$ protein (Tsai et al., 2003). In this model, the nucleotides in P3 that are suggested to interact with $\mathrm{C} 5$ are positioned closer to the P3 loop (the size of P3 in E. coli RNase P RNA is similar to that of L. israelensis ATCC $43119^{\mathrm{T}}$ ). However, if P3 serves as a binding region for $\mathrm{C} 5$, then the available structural data (i.e. comparison of the P3 structure derived from closely related bacterial species, see above) suggest that the interaction between P3 and C5 should not depend on the length of P3. We therefore argue that it is possible that C5 binds to a specific sequence motif in P3. We suggest that it is likely that the 'boxed' residues in Fig. 1 serve as a binding motif for the C5 protein. The extra P3 residues in L. israelensis ATCC $43119^{\mathrm{T}}$ (and in other RNase P RNAs with long P3 helices) 
might be important for structural stabilization and/or be involved in interactions with other factors in the cell. However, this remains to be investigated.

In Bacillus subtilis, RNase P system chemical cleavage footprinting (Loria et al., 1998) and nucleotide analogue modification interference studies (NAIM; Rox et al., 2002) suggest that $\mathrm{P} 12$ and the $\mathrm{C} 5$ protein are in close proximity. Given that the RNase P holoenzyme consists of one RNA subunit and one protein subunit, neither of the two threedimensional models are consistent with an interaction of C5 with both P12 and P3 (Chen et al., 1998; Tsai et al., 2003 and references therein). However, Fang et al. (2001) observed that the B. subtilis RNase P holoenzyme formed tetramers in solution that might rationalize the footprinting and NAIM data. For E. coli RNase P holoenzyme, no tetramers in solution have so far been observed (Fang et al., 2001). Nevertheless, cross-linking between the RNA and the protein subunits in E. coli RNase P holoenzyme has been observed (Sharkady \& Nolan, 2001). The residues at positions 144 and 145 in L. pneumophila sg 1 correspond to the nucleotides in E. coli RNase P RNA that cross-linked to the C5 protein. In this study, we observed major structural variation in P12 in RNase P RNA derived from a large number of Legionella species with respect to size (i.e. number of base pairs), loop size and the number of bulges and their position in P12 (Fig. 1). Taken together, if P12 constitutes a binding site for the RNase $\mathrm{P}$ protein, it might be reoriented as proposed elsewhere (Sharkady \& Nolan, 2001) or perhaps these data might reflect flexibility in the structure of RNase P RNA. Moreover, there is a possibility of identifying C5 amino acid residues that bind to the RNA in P12 by characterizing the rnpA gene from the corresponding Legionella species and looking for co-variation.

Another interesting structural feature is the suggested stemloop structure between P16 and P17. This structural element has previously been described in RNase P RNA derived from Planctomycetes and $\alpha$-Proteobacteria (Brown, 1999), but it has not been observed in RNase P RNA from $\gamma$-Proteobacteria. Although the function of this stem-loop is not known, it is located very close to the domain of RNase $\mathrm{P}$

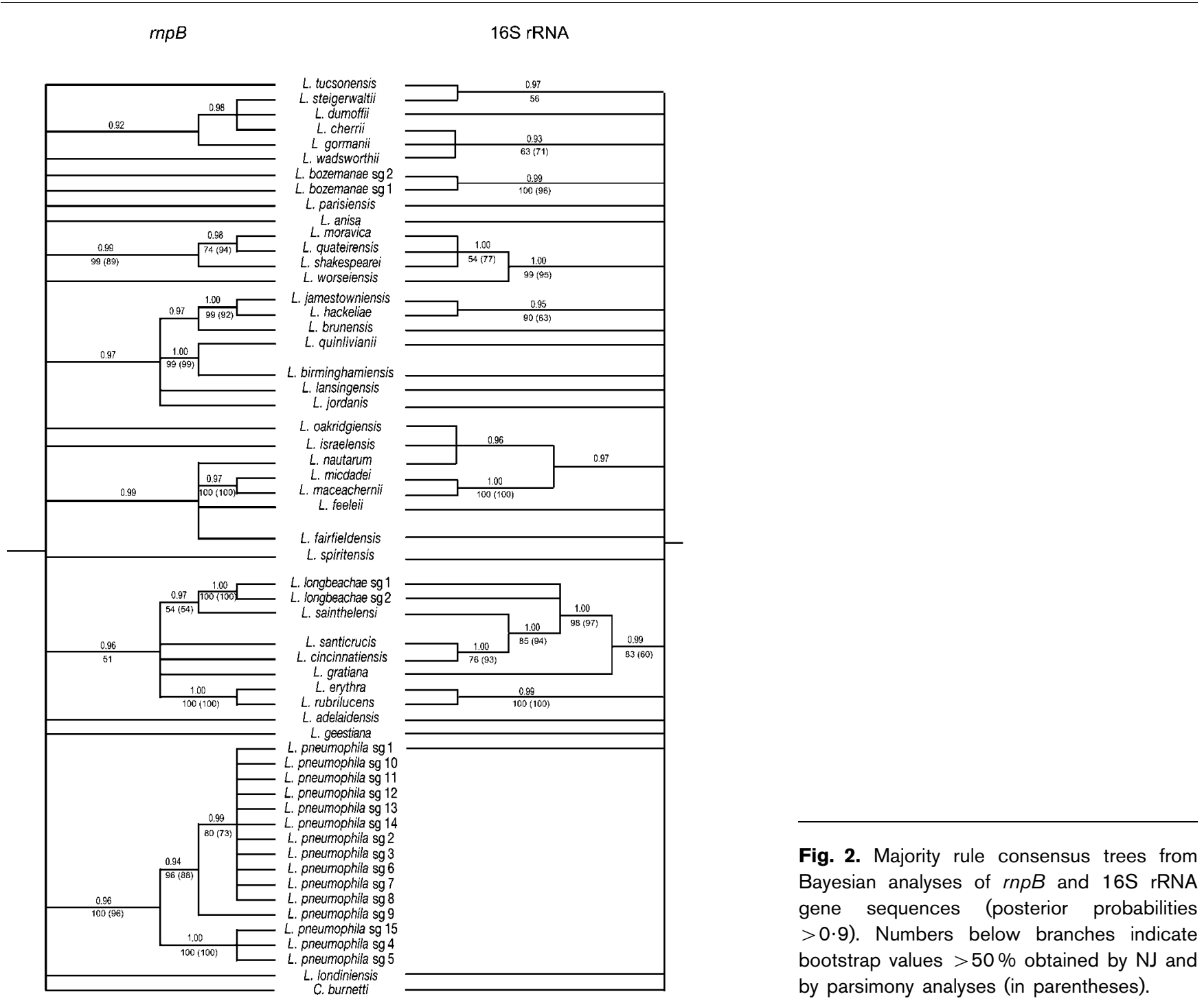


RNA that interacts with the $3^{\prime}$ RCCA motif of the precursor substrates (interacting residues at position 284:G and 285:G in L. pneumophila ATCC $33152^{\mathrm{T}}$ sg 1 in Fig. 1) (Kirsebom \& Svard, 1994). In the structural model of the RNase $\mathrm{P}$ holoenzyme, the RNase $\mathrm{P}$ protein is positioned close to the $\mathrm{P} 15 / 16$ region and therefore raises the possibility that the stem-loop structure between P16 and P17 functions as an anchoring site for the RNase P protein. However, its position in the three-dimensional structure cannot be such that it interferes with the binding of the substrate.

\section{Phylogenetic analysis}

Site-to-site rate variation was modelled separately for each of the genes $r n p B, 16 \mathrm{~S}$ rRNA, $r p o B$ and mip. For the $r n p B$ and $r p o B$ genes, the most adequate model was $\operatorname{TrNef}+\mathrm{I}+\Gamma$, i.e. a Tamura Nei model (Tamura \& Nei, 1993), with equal base frequencies and invariant sites plus a gamma rate distribution. For the mip gene, the GTR $+\mathrm{I}+\Gamma$ model, i.e. General
Time Reversible (Lanave et al., 1984) with invariant sites and a gamma rate distribution (Yang, 1994), was shown to be the most suitable. For the 16S rRNA gene, the most appropriate model was found to be $\mathrm{HKY}+\mathrm{I}+\Gamma$ (Hasegawa et al., 1985). In the Bayesian combined analysis, each gene was assigned its corresponding optimal model with independent parameters and GTR was used in place of TrNef (due to limitation in MrBayes).

The MP, NJ and Bayesian analyses of each gene separately, and for the four genes combined, resulted in similar topologies, although differences were observed. Tree topologies showed that the number of conflicts, above a Bayesian posterior probability of 95, was highest for the comparison between $r p o B$ and mip (eight conflicts), followed by the $16 \mathrm{~S}$ rRNA gene and $r p o B$ (five conflicts), $r m p B$ and mip (four conflicts) and $r p o B$ and $r m p B$ (three conflicts). There were two conflicts between the 16S rRNA gene sequence and mip and between $16 \mathrm{~S}$ rRNA and $r m p B$.

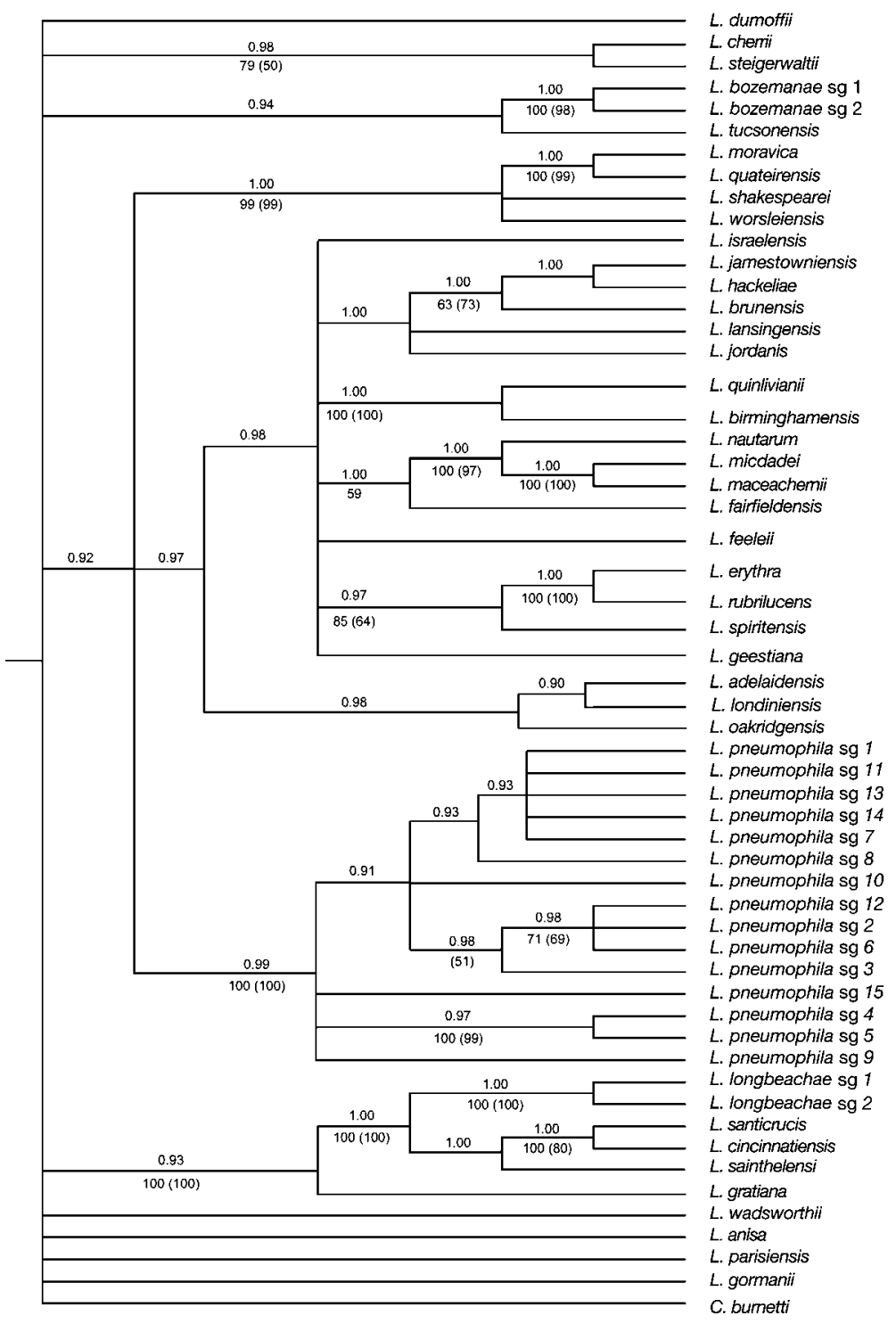

Fig. 3. Majority rule consensus tree from the Bayesian analysis of the combined dataset comprising $r n p B$, mip, 16S rRNA and $r p o B$ gene sequences (posterior probabilities $>0.9$ ). Numbers below branches indicate bootstrap values $>50 \%$ obtained by $\mathrm{NJ}$ and by parsimony analysis (in parentheses). 
Node support (posterior probabilities for Bayesian analyses and bootstrap proportions for MP and NJ) was used to evaluate the phylogenetic utility of the information embedded in the gene sequences. The majority rule consensus trees from the Bayesian analyses of $r p p B$ and $16 \mathrm{~S}$ rRNA gene sequences are shown in Fig. 2. Branches with Bayesian posterior probabilities of $<0.90$ are collapsed and the numbers below the branches indicate the score obtained by bootstrap analysis using $\mathrm{NJ}$ and parsimony algorithms.

Bayesian analysis of 16S rRNA gene sequences from 150 different species representing approximately 55 genera showed that the Legionella species examined form a wellsupported clade and thus constitute a monophyletic group (data not presented).

The phylogenetic analysis of combined datasets (one comprising $r n p B$ together with mip and the other with all four genes) included 39 Legionella species, of which 37 had sequences available for all four genes. The phylogenetic analysis of the four genes together (Fig. 3) and $r n p B$ together with mip (not presented) revealed very similar branching with 18 and 17 well-supported nodes, respectively, i.e. with posterior probabilities of $\geqslant 0 \cdot 95$. The numbers of well-supported nodes in the analyses of each gene sequence alone were 13 for mip, 12 for $16 \mathrm{~S}$ rRNA, 11 for $m p p B$ and five for $r p o B$. The well-supported nodes together comprised 29 species in the analysis of all four genes, 28 species for $r n p B$ together with mip, 25 species for $r n p B, 22$ species for mip, 19 species for $16 \mathrm{~S}$ rRNA and 11 species for $r p o B$. Interestingly, the well-supported nodes derived from $\operatorname{rnp} B$ and mip gene sequences comprised more species than the well-supported nodes from $16 \mathrm{~S}$ rRNA and $r p o B$ gene sequences and therefore contributed most of the phylogenetic signal in the dataset including all four genes.

In our analysis of $r p o B$, we found five fewer nodes of substantial support compared with a previous study (Ko et al., 2002; data not shown). In their presented NJ trees, there were several nodes that were in conflict compared with an analysis of mip gene sequences. In contrast, such conflicts were almost absent in our comparison between $r p o B$ and the other gene sequences. Thus $r p o B$ did not improve the resolution of the phylogenetic tree regarding species, but showed six nodes with significant support within the L. pneumophila species. This is more than was found for the $r p p B$ and mip phylogeny, where only four nodes were observed. However, the $r p o B$ tree is
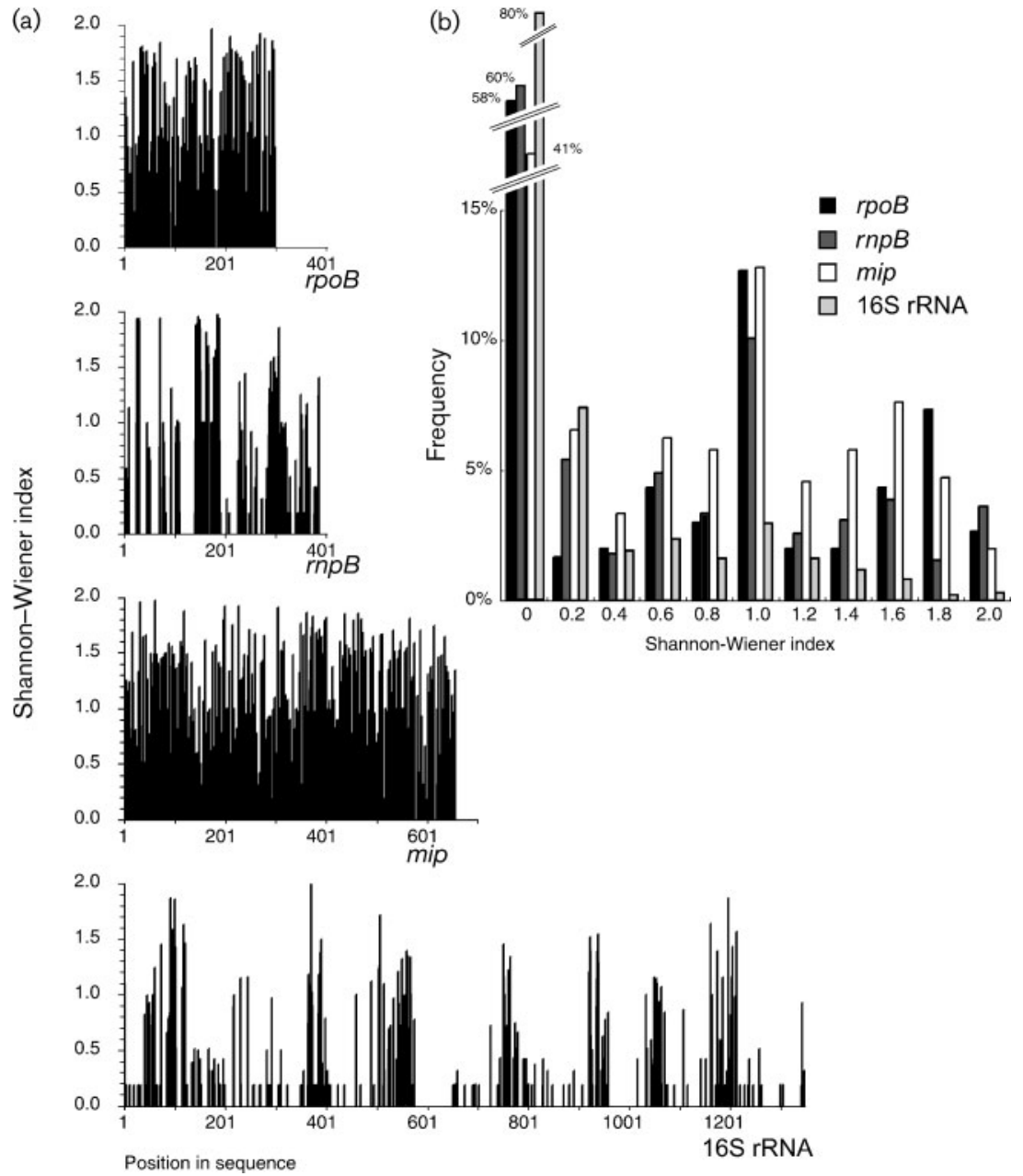

Fig. 4. (a) Results from the ShannonWiener (SW) analysis of the $r p o B, r n p B$, mip and 16S rRNA gene sequences. The SW index shows the sequence variation along the individual genes. (b) Frequencies of sites with specific SW indices are shown. The mean SW index is 0.13 for the $16 \mathrm{~S}$ rRNA gene sequence, 0.38 for $\operatorname{rnp} B, 0.48$ for $r p o B$ and 0.57 for mip. 
in conflict with current taxonomy in which serogroups 4, 5 and 15 comprise one subspecies: L. pneumophila subsp. fraseri (Brenner et al., 1988).

The results from the Shannon-Wiener analysis are presented in Fig. 4(a) as the SW index for each nucleotide position along the genes. The protein coding genes mip and $r р о B$ have a regular high variation, mainly in nucleotides corresponding to the third position of codons, while the $r n p B$ and 16S rRNA genes have conserved domains interspersed with variable and hypervariable regions. The proportions of nucleotide positions with certain information content are shown in Fig. 4(b) and the histograms show that the $16 \mathrm{~S}$ rRNA gene has a lower fraction of nucleotide positions with high information content compared with $r n p B$.

\section{Differentiation of Legionella species}

In $r n p B$, the nucleotide positions with high information content are located in certain loops surrounded by highly conserved regions, a trait that makes $\operatorname{rnp} B$ a promising candidate for the differentiation of bacterial species. A minor evaluation of identification based on $r n p B$ sequence was performed on 15 non- $L$. pneumophila clinical and environmental isolates (Fig. 5). In 12 cases, rnpB-based identification was in agreement with previous phenotypic determinations in a reference laboratory. Two isolates originally identified as $L$. micdadei had $r n p B$ genes identical to those from L. micdadei ATCC $33218^{\mathrm{T}}$ and L. maceachernii ATCC $35300^{\mathrm{T}}$ and could not be further typed by using $r p p B$. For the three isolates with discrepant results, two showed $r n p B$ sequences that were identical to type strains other than those indicated by phenotypic identification. The third isolate, 1829/00, was identified as Legionella gormanii at the reference laboratory from which it was obtained. However, here we show that the $\operatorname{rnp} B$ of this isolate had ten discrepant nucleotide positions compared with the $\operatorname{rnpB}$ of $L$. gormanii ATCC $33297^{\mathrm{T}}$. The 16S rRNA gene sequence was $98 \cdot 8 \%$ similar to that of L. gormanii ATCC $33297^{\mathrm{T}}$ and sequencing of mip generated a sequence identical to that of the type strain, indicating that the correct identity of the isolate was L. gormanii.

These data suggest that the $\operatorname{mp} B$ gene may be useful for the identification of most Legionella species. However, further investigation on intraspecies sequence heterogeneity is required. The $16 \mathrm{~S} \mathrm{rRNA}$ gene sequence is commonly used for the differentiation of closely related species. It is wellcharacterized for a wide variety of organisms and displays enough variable and conserved regions in order to be useful. However, 16S rRNA genes can occur as multiple heterogeneous copies in the genome (Clayton et al., 1995; Nubel et al., 1996; Ueda et al., 1999; Wang \& Wang, 1997) and this can lead to misidentification, due to chimerical sequences, if this heterogeneity is not considered in the design of the assay for genotypic identification. Furthermore, recombination in 16S rRNA genes has been reported as a potential cause of erroneous species identification (Schouls et al., 2003). The 16S rRNA gene is quite large and consists of approximately $1500 \mathrm{bp}$ and may therefore be laborious to sequence when full-length sequencing is necessary. The mip and rpoB genes are protein-encoding and thus the nucleotide at the third position of each codon is often variable (Fig. $4 \mathrm{~b}$ ). This results in the absence of highly conserved regions and therefore hampers the design of primers in assays for genotypic identification.

For the Legionella genus, sequencing of $r n p B$ in combination with other genes can contribute to improved species identification and could be used in MLST. Characterization of $r n p B$ from type strains of all known members of the genus Legionella will further determine the potential of $r n p B$ for species identification. When compared with other genes commonly used for the discrimination of bacteria, the advantages of $r n p B$ lie in the combination of conserved and highly variable sequence regions. Furthermore, $r p p B$ is a

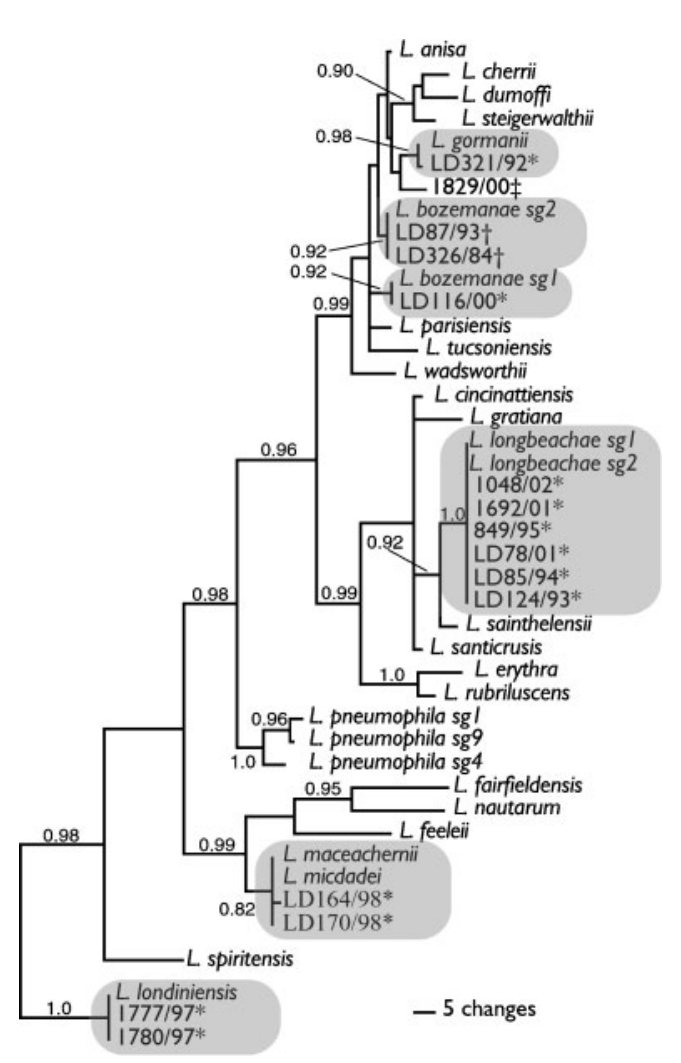

Fig. 5. Consensus tree ( 0.5 probability cut-off $)$ from a Bayesian analysis of $r n p B$ gene sequences from 25 type strains and from 15 clinical and environmental isolates. Branch lengths are proportional to the number of visible changes (i.e. parsimony ACCTRAN optimization). Posterior probabilities above 0.9 are shown on corresponding branches; shaded backgrounds indicate species assignments. Isolates marked with an asterisk $\left({ }^{*}\right)$ received the same assignment as with phenotyping, whereas isolates marked with a dagger $(\dagger)$ received a different assignment using $r n p B$ gene sequences. The identification of LD170/ 98 and LD164/98 as L. micdadei or L. maceachernii does not receive significant posterior probability (only 0.82 ), despite having the identical sequence. 
single copy gene which has been shown to be useful in the differentiation of closely related bacteria (Herrmann et al., 2000; Svard et al., 1994; Tapp et al., 2003).

To conclude, the sequence variation of $r p p B$ separated 37 of 39 Legionella species included in this study. The variation in putative secondary structures provides the possibility of understanding the interaction between RNase P RNA and the C5 protein. Phylogenetic analysis showed that $\operatorname{rnpB}$ clustered more species in nodes with strong branch support than did any of the other three genes, and when combined with mip the phylogenetic utility was further enhanced. Thus, the combination of strictly conserved and hypervariable elements suggests $r n p B$ as useful for species identification and for the phylogenetic analysis of closely related species.

\section{REFERENCES}

Alli, O. A., Zink, S., von Lackum, N. K. \& Abu-Kwaik, Y. (2003). Comparative assessment of virulence traits in Legionella spp. Microbiology 149, 631-641.

Altman, S. \& Kirsebom, L. A. (1999). Ribonuclease P. In The RNA World, pp. 351-380. Edited by R. F. Gesteland, T. R. Cech \& J. F. Atkins. Cold Spring Harbor, NY: Cold Spring Harbor Laboratory.

Brenner, D. J., Steigerwalt, A. G., Epple, P. \& 7 other authors (1988). Legionella pneumophila serogroup Lansing 3 isolated from a patient with fatal pneumonia, and descriptions of L. pneumophila subsp. pneumophila subsp. nov., L. pneumophila subsp. fraseri subsp. nov., and L. pneumophila subsp. pascullei subsp. nov. J Clin Microbiol 26, 1695-1703.

Brown, J. W. (1999). The Ribonuclease P Database. Nucleic Acids Res 27, 314.

Chen, J. L., Nolan, J. M., Harris, M. E. \& Pace, N. R. (1998). Comparative photocross-linking analysis of the tertiary structures of Escherichia coli and Bacillus subtilis RNase P RNAs. EMBO J 17, 1515-1525.

Clayton, R. A., Sutton, G., Hinkle, P. S., Jr, Bult, C. \& Fields, C. (1995). Intraspecific variation in small-subunit rRNA sequences in GenBank: why single sequences may not adequately represent prokaryotic taxa. Int J Syst Bacteriol 45, 595-599.

De Gheldre, Y., Maes, N., Presti, F. L., Etienne, J. \& Struelens, M. (2001). Rapid identification of clinically relevant Legionella spp. by analysis of transfer DNA intergenic spacer length polymorphism. J Clin Microbiol 39, 162-169.

Fang, X. W., Yang, X. J., Littrell, K., Niranjanakumari, S., Thiyagarajan, P., Fierke, C. A., Sosnick, T. R. \& Pan, T. (2001). The Bacillus subtilis RNase P holoenzyme contains two RNase P RNA and two RNase P protein subunits. RNA 7, 233-241.

Feddersen, A., Meyer, H. G., Matthes, P., Bhakdi, S. \& Husmann, M. (2000). GyrA sequence-based typing of Legionella. Med Microbiol Immunol 189, 7-11.

Fields, B. S., Benson, R. F. \& Besser, R. E. (2002). Legionella and Legionnaires' disease: 25 years of investigation. Clin Microbiol Rev 15, 506-526.

Fox, K. F., Brown, A., Fox, A. \& Schnitzer, G. (1991). Tatlockia, a genetically and chemically distinct group of bacteria. Proposal to transfer Legionella maceachernii (Brenner et al.) to the genus Tatlockia, as Tatlockia maceachernii comb. nov. Syst Appl Microbiol $14,52-56$.
Fry, N. K., Warwick, S., Saunders, N. A. \& Embley, T. M. (1991). The use of $16 \mathrm{~S}$ ribosomal RNA analyses to investigate the phylogeny of the family Legionellaceae. J Gen Microbiol 137, 1215-1222.

Gaia, V., Fry, N. K., Harrison, T. G. \& Peduzzi, R. (2003). Sequencebased typing of Legionella pneumophila serogroup 1 offers the potential for true portability in legionellosis outbreak investigation. J Clin Microbiol 41, 2932-2939.

Haas, E. S. \& Brown, J. W. (1998). Evolutionary variation in bacterial RNase P RNAs. Nucleic Acids Res 26, 4093-4099.

Hasegawa, M., Kishino, H. \& Yano, T. (1985). Dating of the humanape splitting by a molecular clock of mitochondrial DNA. J Mol Evol 22, 160-174.

Helbig, J. H., Uldum, S. A., Bernander, S., Luck, P. C., Wewalka, G., Abraham, B., Gaia, V. \& Harrison, T. G. (2003). Clinical utility of urinary antigen detection for diagnosis of community-acquired, travel-associated, and nosocomial legionnaires' disease. J Clin Microbiol 41, 838-840.

Herrmann, B., Pettersson, B., Everett, K. D., Mikkelsen, N. E. \& Kirsebom, L. A. (2000). Characterization of the $r p p B$ gene and RNase P RNA in the order Chlamydiales. Int J Syst Evol Microbiol 50, 149-158.

Huelsenbeck, J. P. \& Crandall, K. A. (1997). Phylogeny estimation and hypothesis testing using maximum likelihood. Annu Rev Ecol Syst 28, 437-466.

Huelsenbeck, J. P. \& Ronquist, F. (2001). MRBAYES: Bayesian inference of phylogenetic trees. Bioinformatics 17, 754-755.

Johansson, K. E., Pettersson, B., Uhlen, M., Gunnarsson, A., Malmqvist, M. \& Olsson, E. (1995). Identification of the causative agent of granulocytic ehrlichiosis in Swedish dogs and horses by direct solid phase sequencing of PCR products from the 16S rRNA gene. Res Vet Sci 58, 109-112.

Jonas, D., Meyer, H. G., Matthes, P., Hartung, D., Jahn, B., Daschner, F. D. \& Jansen, B. (2000). Comparative evaluation of three different genotyping methods for investigation of nosocomial outbreaks of Legionnaires' disease in hospitals. J Clin Microbiol 38, 2284-2291.

Kirsebom, L. A. \& Svard, S. G. (1994). Base pairing between Escherichia coli RNase P RNA and its substrate. EMBO J 13, 4870-4876.

Ko, K. S., Lee, H. K., Park, M. Y., Lee, K. H., Yun, Y. J., Woo, S. Y., Miyamoto, H. \& Kook, Y. H. (2002). Application of RNA polymerase beta-subunit gene $(r p o B)$ sequences for the molecular differentiation of Legionella species. J Clin Microbiol 40, 2653-2658.

Lanave, C., Preparata, G., Saccone, C. \& Serio, G. (1984). A new method for calculating evolutionary substitution rates. J Mol Evol 20, 86-93.

Loria, A., Niranjanakumari, S., Fierke, C. A. \& Pan, T. (1998). Recognition of a pre-tRNA substrate by the Bacillus subtilis RNase P holoenzyme. Biochemistry 37, 15466-15473.

Massire, C., Jaeger, L. \& Westhof, E. (1998). Derivation of the threedimensional architecture of bacterial ribonuclease P RNAs from comparative sequence analysis. J Mol Biol 279, 773-793.

Murray, P. R., Rosenthal, K. S., Kobayashi, G. S. \& Pfaller, M. (2002). Medical Microbiology. St Louis, MI: Mosby.

Nubel, U., Engelen, B., Felske, A., Snaidr, J., Wieshuber, A., Amann, R. I., Ludwig, W. \& Backhaus, H. (1996). Sequence heterogeneities of genes encoding $16 \mathrm{~S}$ rRNAs in Paenibacillus polymyxa detected by temperature gradient gel electrophoresis. J Bacteriol 178, 5636-5643.

O'Connell, W. A., Dhand, L. \& Cianciotto, N. P. (1996). Infection of macrophage-like cells by Legionella species that have not been associated with disease. Infect Immun 64, 4381-4384. 
Pace, N. R. \& Brown, J. W. (1995). Evolutionary perspective on the structure and function of ribonuclease $\mathrm{P}$, a ribozyme. J Bacteriol 177, 1919-1928.

Pannucci, J. A., Haas, E. S., Hall, T. A., Harris, J. K. \& Brown, J. W. (1999). RNase P RNAs from some Archaea are catalytically active. Proc Natl Acad Sci U S A 96, 7803-7808.

Park, M., Yun, S. T., Kim, M. S., Chun, J. \& Ahn, T. I. (2004). Phylogenetic characterization of Legionella-like endosymbiotic Xbacteria in Amoeba proteus: a proposal for 'Candidatus Legionella jeonii' sp. nov. Environ Microbiol 6, 1252-1263.

Posada, D. \& Crandall, K. A. (1998). MODELTEST: testing the model of DNA substitution. Bioinformatics 14, 817-818.

Ratcliff, R. M., Lanser, J. A., Manning, P. A. \& Heuzenroeder, M. W. (1998). Sequence-based classification scheme for the genus Legionella targeting the mip gene. J Clin Microbiol 36, 1560-1567.

Rox, C., Feltens, R., Pfeiffer, T. \& Hartmann, R. K. (2002). Potential contact sites between the protein and RNA subunit in the Bacillus subtilis RNase P holoenzyme. J Mol Biol 315, 551-560.

Schouls, L. M., Schot, C. S. \& Jacobs, J. A. (2003). Horizontal transfer of segments of the 16S rRNA genes between species of the Streptococcus anginosus group. J Bacteriol 185, 7241-7246.

Shannon, C. E. \& Weaver, W. (1949). The Mathematical Theory of Communication. Urbana: University of Illinois Press.

Sharkady, S. M. \& Nolan, J. M. (2001). Bacterial ribonuclease P holoenzyme crosslinking analysis reveals protein interaction sites on the RNA subunit. Nucleic Acids Res 29, 3848-3856.

Sorensen, A. B., Duch, M., Jorgensen, P. \& Pedersen, F. S. (1993). Amplification and sequence analysis of DNA flanking integrated proviruses by a simple two-step polymerase chain reaction method. J Virol 67, 7118-7124.

Svard, S. G., Mattsson, J. G., Johansson, K. E. \& Kirsebom, L. A. (1994). Cloning and characterization of the RNase P RNA genes from two porcine mycoplasmas. Mol Microbiol 11, 849-859.

Swofford, D. L. (2000). PAUP ${ }^{*}$ : Phylogenetic Analysis Using Parsimony (* and other methods). Sunderland, MA: Sinauer Associates.
Tamura, K. \& Nei, M. (1993). Estimation of the number of nucleotide substitutions in the control region of mitochondrial DNA in humans and chimpanzees. Mol Biol Evol 10, 512-526.

Tapp, J., Thollesson, M. \& Herrmann, B. (2003). Phylogenetic relationships and genotyping of the genus Streptococcus by sequence determination of the RNase P RNA gene, rnpB. Int J Syst Evol Microbiol 53, 1861-1871.

Tsai, H. Y., Masquida, B., Biswas, R., Westhof, E. \& Gopalan, V. (2003). Molecular modeling of the three-dimensional structure of the bacterial RNase P holoenzyme. J Mol Biol 325, 661-675.

Ueda, K., Seki, T., Kudo, T., Yoshida, T. \& Kataoka, M. (1999). Two distinct mechanisms cause heterogeneity of $16 \mathrm{~S}$ rRNA. J Bacteriol 181, 78-82.

Valsangiacomo, C., Baggi, F., Gaia, V., Balmelli, T., Peduzzi, R. \& Piffaretti, J. C. (1995). Use of amplified fragment length polymorphism in molecular typing of Legionella pneumophila and application to epidemiological studies. J Clin Microbiol 33, 1716-1719.

Verissimo, A., Morais, P. V., Diogo, A., Gomes, C. \& da Costa, M. S. (1996). Characterization of Legionella species by numerical analysis of whole-cell protein electrophoresis. Int J Syst Bacteriol 46, 41-49.

Wang, G. C. \& Wang, Y. (1997). Frequency of formation of chimeric molecules as a consequence of PCR coamplification of 16S rRNA genes from mixed bacterial genomes. Appl Environ Microbiol 63, 4645-4650.

Wiener, N. (1949). Extrapolation, Interpolation, and Smoothing of Stationary Time Series: with Engineering Applications. New York: Wiley.

Yang, Z. H. (1994). Maximum likelihood phylogenetic estimation from DNA sequences with variable rates over sites: approximate methods. J Mol Evol 39, 306-314.

Yu, V. L., Plouffe, J. F., Pastoris, M. C. \& 8 other authors (2002). Distribution of Legionella species and serogroups isolated by culture in patients with sporadic community-acquired legionellosis: an international collaborative survey. J Infect Dis 186, 127-128. 